\title{
ACERCA DE LA CONDICIÓN DE INCOMPATIBILIDAD DE SERVIDORES PÚBLICOS
}

\author{
About incompatibility condition of public servants \\ José Miguel MADERO ESTRADA \\ Oscar GUTIÉRREZ AGÜERO'
}

\section{Sumario:}

I. Introducción. II Dimensión sustantiva de la condición de incompatibilidad según el tipo de servidores públicos. III. Estudio de casos de incompatibilidad e inelegibilidad en cargos de elección popular. IV. La incompatibilidad parlamentaria local. V. Conclusión. VI. Fuentes de consulta.

Resumen. Con énfasis en el Estado de Nayarit, el ensayo lleva por título "Acerca de la condición de incompatibilidad de servidores públicos", tema central que se expone desde una dimensión sustantiva tomando en cuenta el tipo o carácter de servidor público, según corresponda a aquellos que llevan a cabo una función de origen electoral, o bien a los que son designados directamente por algún órgano estatal competente, con el objeto de examinar, a la luz de la doctrina y la legislación, las limitaciones que deben imponerse a quienes, simultáneamente, pretendan desempeñar un segundo puesto, pues tal hecho o conducta afecta seriamente el principio de división de poderes y constituye una falta al deber ético de dedicación completa a una sola función.

El ensayo se extiende al estudio de casos de incompatibilidades de servidores públicos federales, estatales y municipales que, ostentando un cargo de elección popular, buscan acceder a otro de la misma naturaleza.

Finalmente, se realiza un examen jurídico sobre la incompatibilidad parlamentaria local, concluyendo en la necesidad de legislar de manera más integral para evitar que conflictos de interés que desafían la libertad e independencia con que deben actuar los representantes populares.

Palabras clave. Incompatibilidad, inelegibilidad, servidor público y cargo de elección popular.

Abstract. With an emphasis on the state of Nayarit, essay entitled "About the status of public servants incompatibility" central theme that is exposed from a substantive dimension taking into account the type or a public official, as appropriate for those who perform a function of electoral origin, or those who are directly appointed by a competent State body in order to

1 Profesor de la Universidad Autónoma de Nayarit de su Unidad Académica Facultad de Derecho, de la que fue su Director. Reconocimiento con perfil PROMEP y miembro del Sistema Nacional de Investigadores nivel 1. Magistrado del Tribunal Superior de Justicia del Estado de Nayarit, de su Sala Constitucional-Electoral.

2 Abogado; Juez Instructor del Tribunal Electoral del Estado de Nayarit y actual Secretario de Estudio y Cuenta adscrito a la Secretaría General de Acuerdos del Tribunal Superior de Justicia del Estado de Nayarit.

Fernández Ruíz, Jorge, Poder Legislativo, Porrúa, UNAM, México, 2010, pp. 263 y ss. 
examine, in the light of the doctrine and legislation, the limitations to be imposed on those who are simultaneously seeking to play a second place, for such act or behavior seriously undermines the principle of separation of powers and is an ethical duty lack complete dedication to a single function.

The trial extends to cases of incompatibilities study of federal civil servants, state and city, boasting popular public office, seeking access to other of the same nature.

Finally, we performed a legal review of the local parliamentary incompatibility, concluding on the need for more comprehensive legislation to prevent conflicts of interest that challenge freedom and independence that people's representatives must act.

Keywords. Incompatibility, ineligibility, public servant, position of popular election.

\section{INTRODUCCIÓN}

En este estudio se analiza el sistema de incompatibilidades de los servidores públicos, haciendo un planteamiento general respecto al sistema previsto en la Constitución Política de Nayarit y las leyes de la materia, con la finalidad de conocer la regulación y comportamiento de esta figura dentro del ámbito de las funciones legislativa, administrativa, judicial y en los Ayuntamientos.

Particularmente, nos detendremos en examinar la incompatibilidad como un sistema de interferencia en aquellos servidores públicos que buscan obtener un cargo de representación popular, profundizando en lo que respecta al estatuto parlamentario local, por lo que se incluye un análisis de su autonomía reglamentaria.

\section{DIMENSIÓN SUSTANTIVA DE LA CONDICIÓN DE INCOMPATIBILIDAD SEGÚN EL TIPO DE} SERVIDORES PÚBLICOS

La incompatibilidad suele ser una figura constitucional que tiene por objeto asegurar que una vez realizado un nombramiento o verificada una elección popular, los servidores públicos que hayan resultado designados o electos no tengan interferencias en el desarrollo de las funciones encomendadas, debido al ejercicio de otra función.

Trata pues esta figura del cumplimiento de un requisito indispensable para el ejercicio del poder, más no como un mecanismo que tenga por objeto proteger la regularidad del proceso electoral, ya que en este caso estaríamos en presencia de un conjunto de reglas que determinan un perfil básico para aspirar a ocupar un cargo representativo. Sin embargo, entre ambas figuras hay vasos comunicantes.

En efecto, mientras la incompatibilidad tiene como finalidad garantizar que las funciones públicas originadas o no por un nombramiento proveniente de los electores, se realice sin mediar ninguna influencia ni confusión entre poderes, la inelegibilidad, en cambio, es la condición de una persona afectada por alguna de las causas señaladas en las leyes, que la hacen inidónea para ocupar un cargo electoral, por lo que no puede ser proclamado candidato electo. ${ }^{3}$

\footnotetext{
3 FERNÁNDEZ RUÍZ, Jorge, Poder Legislativo, Porrúa, UNAM, México, 2010, pp. 263 y ss. 
Cabe señalar, que otro aspecto inherente al desempeño de una función, se encuentra en la inhabilitación a la que se considera como una especie de sanción accesoria como consecuencia de haber realizado una conducta delictiva, en razón de lo cual el servidor público estará impedido a ejercer cualquier cargo público, por el término que fije la sanción. ${ }^{4}$

Sin embargo, en materia electoral se ha distinguido entre causas de inelegibilidad y causas de incompatibilidad lo que deviene oportuno dimensionar.

Para precisar su objeto, por elegibilidad se entiende a la condición de una persona respecto de un cargo de elección, en el momento en que no cumple con los requisitos establecidos por la legislación aplicable para desempeñarlo, o bien se encuentra en alguna de las hipótesis de los impedimentos previstos en la misma, para tal efecto. Así, podemos afirmar que la inelegibilidad es un vicio por el cual una persona está impedida para contender en elecciones constitucionales e inclusive, si llegare a ser elegida, puede estar legalmente impedida a ocupar el cargo. ${ }^{5}$

La incompatibilidad, por su parte, tiene lugar al surtirse impedimentos que no permiten ejercer un cargo de elección popular causados por desempeñar simultáneamente otra función o actividad. En ese sentido, el Constituyente local establece de manera limitativa un catálogo de puestos y cargos relevantes que son incompatibles con aquellos de elección popular y, en consecuencia, no es dable aspirar a ellos sin haberse separado dentro del término fijado por la Constitución. ${ }^{6}$

Una vez habiendo delimitado esas diferencias, conviene dejar apuntado que los ciudadanos cuentan con derechos políticos para tener acceso, en condiciones de igualdad, a las funciones públicas de su país, y corresponde a la Constitución y a las leyes consagrar los derechos de votar y ser votado para todos los cargos de elección popular, conforme a las cualidades establecidas por el legislador. ${ }^{7}$

Es por ello que tales diferencias no esconden sus ligas comunicantes, toda vez que, si bien se percibe algunas restricciones al quehacer público de las personas, éstas tienen por finalidad garantizar la plena eficacia del principio de división de funciones e independencia de los poderes públicos, pues de no hacerlo se generarían situaciones anormales que serían difíciles de remediar.

De tal forma, se justifica prohibir o condicionar que alguien pueda desempeñar al mismo tiempo dos o más cargos públicos, ya que resulta incompatible a la naturaleza de la función pública, siendo indispensable al efecto cesar en alguna de las ocupaciones mientras dure el nuevo encargo, mandato que surte efecto tanto para los representantes populares como para los servidores públicos por designación, de suerte que el término para la separación previa es perentorio y fatal.

Este tema no es ajeno al constitucionalismo de un Estado Federal, motivo por el cual, la Constitución de cualquier entidad federativa proporciona tanto las bases generales de in-

\footnotetext{
4 DOSAmANTES TERÁN, Jesús Alfredo, Diccionario de Derecho Electoral, Porrúa, México, 2004, p. 178.

5 Jurisprudencia 14/2009, Sala Superior del Tribunal Electoral del Poder Judicial de la Federación, Gaceta de Jurisprudencia y Tesis en materia electoral, año 3, número 5, 2010, pp. 48 y 49.

${ }^{6}$ La separación absoluta del desempeño de un cargo público compatible, para poder ser electo válidamente, se cumple mediante una licencia sin goce de sueldo, en razón de que se prescribe constitucionalmente no estar en ejercicio de algún cargo comprendido dentro del catálogo, mas no la calidad de servidor público. Véase Jurisprudencia y tesis relevantes 1997-2005, compilación oficial, Tribunal Electoral del Poder Judicial de la Federación, p. 533, Tesis XXIV/2004.

7 Consúltese artículo 21.2 de la Declaración Universal de Derechos Humanos de 1948.
} 
compatibilidad parlamentaria, como un catálogo de cargos relevantes, así como el término en que deben sus titulares estar separados para poder ocupar otro de origen electoral.

Bajo esta aproximación, la Constitución de Nayarit, en los artículos 31, 62, fracción III y 109, fracción IV, impone a ciertos servidores públicos el deber de separarse del cargo que ostentan, debiendo hacerlo de manera oportuna, objetiva y acreditable para evitar consecuencias drásticas, tanto administrativas como penales. ${ }^{8}$

Mientras que el artículo 31 se refiere a la incompatibilidad del legislador, los otros numerales de la Constitución, aluden a sendos requisitos de elegibilidad, puesto que las personas que se hallen dentro de esos supuestos no podrán ser electas si no se separan de sus cargos o del servicio público noventa días antes de la elección, precepto(s) que interpretado(s) correctamente, debe conducir a estimar que el vínculo entre el candidato y el cargo del que se debe separar, debe desaparecer decisivamente y sin duda alguna, dejando de tener cualquier relación con la actividad que desempeñaba. ${ }^{9}$

Ahora bien, el catálogo de puestos comprende a los siguientes funcionarios: secretario o subsecretario del Despacho del Poder Ejecutivo estatal o federal; presidente municipal, síndico o regidor; secretario, tesorero o director de alguna dependencia del Ayuntamiento; Fiscal General, diputado local o federal, senador de la República, delegados, subdelegados o titulares de las dependencias o entidades de la Administración Pública federal en el estado; ministro, magistrado o juez del Poder Judicial de la Federación o del estado, miembro del Consejo de la Judicatura estatal o federal o integrante de los organismos electorales, con excepción de los representantes de los partidos políticos; titular de organismo autónomo o descentralizado federal, estatal o municipal; así como los miembros en servicio activo en el Ejército Nacional o Armada de México.

Ligado a lo anterior, la citada Constitución local establece a modo de principio republicano de gobierno, una regla general de compatibilidad de naturaleza electoral, en los siguientes términos:

Artículo 137....

(...)

Nadie en el Estado podrá desempeñar dos o más cargos de elección popular, pero el interesado puede elegir el que le convenga. Una vez que el servidor público comience a ejercer el cargo por el que haya optado, el otro quedará sin efectos.

Ese dispositivo constitucional prohíbe entonces la acumulación simultánea de cargos de representación popular, al conferir un derecho estrictamente personal dirigido a aquellos que pueden optar libremente por elegir el cargo que más les convenga si por alguna circunstancia tuvieran que hacerlo al ostentar uno y haber sido electos popularmente para ejercer otro en el futuro inmediato. Sin embargo, ese derecho, queda circunscrito únicamente a cargos de elección popular, ya que por su finalidad intrínseca tiene por objeto proteger el principio de división de poderes y el ejercicio de derechos políticos, en razón de lo cual no puede resultar aplicable en aquellos casos en que la persona deba optar por elegir entre un

\footnotetext{
8 Véase jurisprudencia 14/2009, SEPARACIÓN DEL CARGO. SU EXIGIBILIDAD ES HASTA LA CONCLUSIÓN DEL PROCESO ELECTORAL (LEGISLACIÓN DE MORELOS Y SIMILARES). Jurisprudencia 01/2002 PROCESO ELECTORAL. CONCLUYE HASTA QUE EL ÚLTIMO ACTO O RESOLUCIÓN DE LA ETAPA DE RESULTADOS ADQUIERE DEFINITIVIDAD (LEGISLACIÓN DEL ESTADO DE MÉXICO Y SIMILARES).

9 Véase Justicia Electoral, Revista del Tribunal Electoral del Poder Judicial de la Federación, suplemento 6, año 2003, p. 129. Tesis LVIII/2002.
} 
cargo de designación o uno de elección, toda vez que la Constitución prohíbe ocupar funciones remuneradas incompatibles en un estado democrático.

De esta guisa, dentro del artículo 137 queda comprendido, por igual, la asunción a cargos de elección popular de gobernador, diputados y Ayuntamientos, como también a quienes, para esos efectos, vengan desempeñándose como diputado federal, senador de la República o presidente de los Estados Unidos Mexicanos.

Sabido es que las leyes electorales generalmente estipulan que para ser elegibles a los cargos de elección popular, podrán serlo los ciudadanos del estado que teniendo la calidad de electores, reúnan los requisitos establecidos en la Constitución y las leyes. En el caso de Nayarit, en su artículo 223, el legislador desglosa un conjunto de prohibiciones aplicables a los ciudadanos aspirantes, precandidatos y candidatos, entre las que destacan realizar actividades de proselitismo fuera de los tiempos correspondientes a las precampañas y campañas; utilizar emblemas o lemas partidistas sin autorización, así como ostentarse con carácter de precandidato o candidato o con la denominación de un cargo público sin tenerlo legalmente; entre otros. Quienes no cumplan ese código de conducta, pueden ser declarados inelegibles, una vez seguido el procedimiento respetivo.

Para determinar el alcance que otorga la Constitución al tema de las incompatibilidades, otros dispositivos constitucionales condicionan expresamente poder ocupar ciertos cargos públicos, como en caso de los magistrados del Poder Judicial y del Fiscal General (antes procurador general de justicia), según se desprende de los artículos 94 y 95 de la Constitución, preceptos que se adminiculan con el artículo 83, fracción VI. ${ }^{10}$

Artículo 83. Para ser designado Magistrado del Tribunal Superior de Justicia se necesita:

(...)

VI.- No haber sido secretario del despacho del Poder Ejecutivo, Fiscal General o diputado local, durante el año previo al día de la designación.

Artículo 94. Para ser designado Fiscal General, se necesitan los mismos requisitos que para ser secretario del despacho del Poder Ejecutivo, salvo lo previsto para el caso de la profesión, pues en este caso deberá contar invariablemente con título de licenciado en derecho.

La propuesta y ratificación respectivas, se harán conforme las bases estipuladas en esta Constitución y en las leyes aplicables. El Fiscal General podrá ser removido solamente en términos del Título Octavo de esta Constitución.

Artículo 95. No podrá ser Fiscal General, quien haya ocupado el cargo de Magistrado del Tribunal Superior de Justicia o Consejero de la Judicatura, durante el año previo al día de la designación.

Frente a todo ello, resulta obvia la existencia de catálogos de puestos públicos relevantes en los tres órdenes de autoridad -Federación, estado y municipios- así como de los organismos electorales y autónomos, por lo que las reglas de incompatibilidad deben aplicarse para cada caso en concreto. ${ }^{11}$

\footnotetext{
${ }^{10}$ Todas estas disposiciones constitucionales se reformaron según publicación en el Periódico Oficial Órgano del Gobierno del Estado de Nayarit, de fecha 21 de enero de 2013, con el objeto de introducir la figura del Fiscal General, en sustitución de la de Procurador General de Justicia.

${ }^{11}$ En atención a una interpretación extensiva y abierta, algunas legislaciones establecen incompatibilidades que no se aplican solamente a partir del inicio del desempeño de un cargo público, sino que sus efectos son posteriores a la fecha de la conclusión del periodo para el cual fue designado el funcionario, como es el caso del titular del Órgano Superior de Fiscalización quien, durante el año siguiente a la conclusión de su ejercicio, estará impedido para ocupar algún cargo de elección popular local, así como para desempeñar empleo, cargo o comisión dentro de alguna de las entidades o dependencias de los sujetos de fiscalización a los que 
Sin embargo, atípicamente, durante muchos años de práctica parlamentaria, se ha fomentado que de forma más específica las incompatibilidades administrativas se prevean dentro del decreto anual del presupuesto de egresos del estado, en vez de que se haga en las respectivas leyes orgánicas de los poderes y en la ley municipal.

A ese respecto, el artículo 54 del presupuesto para el ejercicio fiscal de 2013, señala: ${ }^{12}$

Artículo 54. Queda prohibido el desempeño simultáneo de dos o más empleos, cargos o comisiones por los que se disfrute sueldo del Estado o de los Municipios.

Cuando sean estrictamente necesarios los servicios de un servidor público en los ramos de la educación, beneficencia o salubridad pública, dicho empleado podrá ocupar este tipo de funciones conservando todos sus derechos laborales en su plaza original y seguirá acumulando antigüedad por el tiempo que dure en su nuevo encargo, pero no percibirá retribución alguna por la plaza que desocupe temporalmente.

Los titulares de las dependencias y entidades serán responsables de verificar esta situación laboral de los empleados a su cargo a efecto de evitar los pagos indebidos, debiendo notificar, en su caso, a la Secretaría para la generación de la baja en la nómina que corresponda.

Por lo visto, si bien es cierto que el legislador nayarita reproduce la prohibición de incompatibilidad comprendiendo en ella el ejercicio simultáneo de dos o más empleos, cargos o comisiones por cuyo desempeño se disfrute de sueldo estatal o municipal, también es cierto que más allá de la naturaleza jurídica del presupuesto anual, exceptúa de esa prohibición a tres ramos: educación (como es el caso de las funciones docentes), beneficencia (como son las actividades en fundaciones o asociaciones sin fines de lucro) o salubridad pública (las actividades laborales de médicos, enfermeras o promotores), pues al darse estos supuestos de excepción, los servidores públicos conservarán todos sus derechos laborales en su plaza original, inclusive acumulando antigüedad por el tiempo que dure su nuevo encargo, pero sin obtener retribución alguna en la plaza que desocupen.

Es en el ramo judicial donde sí existe una mayor claridad del régimen de incompatibilidades porque llega a comprender tanto las funciones públicas como las privadas, tal como enseguida se expone:

alude esta ley. Durante ese año, el Auditor General gozará de un haber por retiro similar al monto del salario que percibía a la fecha de conclusión. Del mismo modo, los magistrados y jueces tienen prohibido desempeñar alguna otra función dentro del periodo de que disfruten del haber por retiro. Véanse al respecto las leyes del Órgano Superior de Fiscalización y Orgánica del Poder Judicial, vigentes en el estado de Nayarit.

${ }^{12}$ Véase Periódico Oficial, Órgano del Gobierno del Estado, del 27 de diciembre de 2012, sección primera, número 092, que contiene el Presupuesto de Egresos del Estado Libre y Soberano de Nayarit, para el ejercicio fiscal 2013, bajo el subtítulo: “disposiciones de racionalidad, plazas, sueldos y salarios (límites)". 


\begin{tabular}{|c|c|}
\hline Constitución Política de Nayarit & Ley Orgánica del Poder Judicial \\
\hline $\begin{array}{l}\text { Artículo 90. Los magistrados del Tribunal Superior de Jus- } \\
\text { ticia, los Jueces y Secretarios, en ejercicio, no podrán, en } \\
\text { ningún caso, aceptar ni desempeñar empleo o encargo de la } \\
\text { Federación, del Estado, Municipios o de particulares, salvo } \\
\text { en instituciones científicas, docentes, literarias o de benefi- } \\
\text { cencia. }\end{array}$ & $\begin{array}{l}\text { Artículo 63. } \\
\text { Los servidores públicos judiciales están impedidos para: } \\
\text { 1. Ejercer la profesión de licenciado en derecho, por sí } \\
\text { o por interpósita persona, a excepción de la defensa de } \\
\text { causas propias, de su cónyuge, concubina o concubinario, } \\
\text { ascendientes, descendientes y colaterales hasta el cuarto } \\
\text { grado. } \\
\text { 2. Desempeñar el cargo de tutores, curadores, albaceas, } \\
\text { depositarios, administradores, o cualesquier otra activi- } \\
\text { dad incompatible con la función judicial, salvo en asuntos } \\
\text { de carácter personal. } \\
\text { 3. Ejercer funciones como síndicos, interventores, árbitros } \\
\text { y/o peritos. } \\
\text { 4. Fungir como ministro de algún culto religioso. } \\
\text { 5. Desempeñar funciones directivas en partidos o agrupa- } \\
\text { ciones políticas. } \\
\text { Artículo } 64 \text {. } \\
\text { 1. Los magistrados del Tribunal Superior de Justicia, los } \\
\text { jueces y secretarios, así como los integrantes del Consejo } \\
\text { de la Judicatura, en ejercicio, no podrán en ningún caso } \\
\text { aceptar ni desempeñar empleo o encargo de la federación, } \\
\text { del estado, municipio o de particulares, salvo los cargos } \\
\text { en asociaciones científicas, docentes, literarias o de bene- } \\
\text { ficencia. } \\
\text { 2. Las personas que hayan ocupado el cargo de magistrado } \\
\text { o juez, no podrán, dentro del periodo de que disfrutan del } \\
\text { haber por retiro, actuar como patronos, abogados o repre- } \\
\text { sentantes en cualquier proceso ante los órganos del Poder } \\
\text { Judicial del Estado, a excepción de la defensa de causas } \\
\text { propias, de su cónyuge, concubina o concubinario, ascen- } \\
\text { ministración de justicia o auxiliar de ésta podrá recaer en } \\
\text { ascendientes, descendientes, cónyuges, concubina o con- } \\
\text { cubinario, colaterales dentro del cuarto grado por con- } \\
\text { sanguinidad, segundo por afinidad o con parentesco civil, } \\
\text { con los servidores que hagan la designación. } \\
\text { 3. Los impedimentontes y colaterales hasta el cuarto grado. } \\
\text { funcionarios judiciales de referencia que gocen de licen- } \\
\text { cia. } \\
\text { 4. La infracción a lo previsto en los párrafos anteriores, } \\
\text { será sancionada con la pérdida del respectivo cargo den- } \\
\text { tro del Poder Judicial, así como de las prestaciones y be- } \\
\text { neficios que en lo sucesivo correspondan por el mismo, } \\
\text { independientemente de las demás sanciones que las leyes } \\
\text { prevean. }\end{array}$ \\
\hline
\end{tabular}

De ese bloque, puede arribarse a la conclusión de que se trata de un conjunto de incompatibilidades no únicamente de jerarquía constitucional, sino también las complementadas armónicamente por el legislador ordinario, conformando así las de carácter jurídico y ético. Igualmente, un buen número trata de incompatibilidades absolutas (artículos 63 párrafos 3 , 4 y 5, y 65) y unas cuantas son relativas (artículo 63 párrafos 1 y 2). 
Cabe hacer notar que en el régimen judicial, a diferencia de otros entes públicos, la infracción a lo previsto en dichas disposiciones, será sancionada con la pérdida del respectivo cargo dentro de la judicatura, así como de las prestaciones y beneficios que en lo sucesivo correspondan por el mismo, independientemente de las demás sanciones que las leyes prevean. ${ }^{13}$

Ahora bien, otra característica es que esa lista de incompatibilidades puede tener lugar tanto al inicio del cargo en sede judicial o bien durante su desempeño. Igualmente, se regulan aquellas adquiridas por una vinculación directa o indirecta con el desempeño de funciones o profesiones particulares (abogados, patronos, síndicos, ministros de culto, etc.); también con el desarrollo de funciones directivas de carácter político (partidos y agrupaciones políticas) y tratándose de aquellos nombramientos prohibitivos por el parentesco en favor de familiares o parientes dentro del aparato judicial (artículo 65).

En resumen, independientemente de las formas que puede adoptar esta figura en las legislaciones, es obvio que los motivos para limitar a que un servidor público obtenga, a un mismo tiempo, un segundo puesto, radica en el hecho de que tiene la obligación fundamental de dedicarse de tiempo completo al desempeño de sola una función por lo que expresa marcadamente un deber ético de los servidores públicos. Así, las formas de incompatibilidad atendiendo al tipo de servidores públicos, pueden ser en razón del horario, por razones físicas, por razón del servicio, función o de ubicación. Excepcionalmente, como ya vimos, puede ser también las de carácter electoral cuando debe el electo, tiene que decidirse por alguno de los cargos que va a desempeñar.

\section{ESTUDIO DE CASOS DE INCOMPATIBILIDAD E INELEGIBILIDAD EN CARGOS DE ELECCIÓN} POPULAR

Este apartado tiene el propósito de analizar las incompatibilidades de servidores públicos que ostentando un cargo de elección popular, buscan acceder a otro de la misma naturaleza.

Para ello, es importante señalar, que el derecho a ser votado, es un derecho fundamental de carácter político-electoral, que tiene sustento constitucional de donde emanan las calidades para su ejercicio por parte de los ciudadanos.

Consecuentemente, el derecho a ser votado no es absoluto, sino que está sujeto a las regulaciones o limitaciones legales, bajo la condición de que las limitaciones impuestas por el legislador no sean irrazonables ni desproporcionadas. De esa forma, la ley dispone que solo aquellas personas que cumplan con ciertas cualidades puedan ejercerlo, o incluso prohibirlo, instaurando un régimen de incompatibilidades. A ese respecto, la Corte Interamericana de Derechos Humanos en el caso Jorge Castañeda Gutman14 arribó a la conclusión de que las restricciones y requisitos para ejercitar el derecho político-electoral en su modalidad de voto pasivo o derecho a ser votado, per se no constituyen una restricción indebida, siempre y

\footnotetext{
${ }^{13}$ En el Tribunal Superior de Justicia del Estado de Nayarit, obra en antecedentes, resolución de fecha 31 de julio de 2002, mediante la cual el pleno de dicho órgano jurisdiccional determinó que un magistrado incurrió en la infracción al impedimento previsto por el entonces artículo 90 de la Constitución, imponiéndole como sanción única la pérdida del cargo, así como las prestaciones y beneficios que le correspondían. La sanción tuvo lugar debido a que dicho magistrado, habiendo fungido hasta ese momento como presidente del tribunal, fue designado por el gobernador del estado al cargo de secretario general de gobierno, lo cual era prohibido por el citado precepto constitucional. FUENTE: Secretaría de Acuerdos del Tribunal Superior de Justicia.

14 Consultable en: http://www.corteidh.or.cr/expediente_caso.cfm?id_caso=295 
cuando se cumplan con ciertos requisitos, a saber: 1. Legalidad de la medida restrictiva. Esto es que la restricción se encuentre claramente establecida en la ley; 2 . Finalidad de la medida restringida; y 3. Necesidad de una sociedad democrática y proporcional de la medida restrictiva.

En esa tesitura, se puede entender a las cualidades para ocupar un cargo de elección popular como la condición inherente a la persona para ejercer un cargo de elección popular (ser ciudadano nayarita, contar con cierta edad, etc.) y como incompatibilidad a los hechos o circunstancias que impiden el ejercicio de un derecho que ya se tiene, siendo su objetivo el de garantizar la imparcialidad de los servidores públicos y la equidad en la contienda electoral.

\section{III.1 Incompatibilidad de los miembros del Ayuntamiento}

1. Cuando alguien se encuentre en ejercicio del cargo de Presidente Municipal:

a) Para ser gobernador, debe separarse del cargo por lo menos 90 días antes de la elección. ${ }^{15}$

b) Para ser diputado local, debe separarse del cargo lo menos 90 días antes de la elección. ${ }^{16}$

c) Para ser senador o diputado federal, debe separarse definitivamente de su cargo 90 días antes de la elección. ${ }^{17}$

d) Para ser presidente de la República, la Constitución federal, contrario a los requisitos para ser gobernador, diputado o senador, no exige la separación del cargo para poder ser presidente de la Republica; sin embargo, en esa hipótesis debe aplicarse lo señalado por el último párrafo del artículo 137 de la Constitución local y por el artículo 125 de la Constitución federal, los cuales establecen elegir el cargo que convenga a la persona que se encuentra en ese supuesto. ${ }^{18}$

2. Cuando una persona se encuentre ocupando los cargos municipales de síndico o regidor:

a) Para ser gobernador, requiere separarse del cargo por lo menos 90 días antes de la elección. ${ }^{19}$

${ }^{15}$ MADERO ESTRADA, José Miguel, Guía Temática de la Constitución, UAN, Unidad Académica Facultad de Derecho, 2012, pp. 30-31. Artículo 62, fracción III, de la Constitución Política del Estado Libre y Soberano de Nayarit (en adelante por sus siglas CPELSN).

${ }^{16}$ Véase artículo 29 de la CPELSN. En el caso de los servidores públicos del Poder Judicial y Consejo de la Judicatura Estatal y Federal, así como los integrantes de los organismos electorales, el término de su separación se computará un año antes de la elección.

17 Véase artículos 55 y 59 de la Constitución Política de los Estados Unidos Mexicanos (por sus siglas CPEUM). En ese sentido, los secretarios del Gobierno de los estados y del Distrito Federal, los magistrados y jueces federales o del estado o del Distrito Federal, así como los presidentes municipales y titulares de algún órgano político-administrativo en el caso del Distrito Federal, no podrán ser electos en las entidades de sus respectivas jurisdicciones, si no se separan definitivamente de sus cargos noventa días antes del día de la elección.

${ }^{18}$ Véanse artículos 137 de la CPELSN y 125 de la CPEUM.

19 Véase, artículo 62, fracción III, de la CPELSN. 
b) Para ser diputados locales, necesita separarse del cargo por lo menos 90 días antes de la elección. ${ }^{20}$

c) Para ser diputado federal o senador, ni la Constitución federal, ni el Código Federal de

Instituciones y Procedimientos Electorales, imponen al síndico o regidores la obligación de separase del cargo para contender por dichos cargos, por lo que, en todo caso, como en los supuestos anteriores, se aplica la regla establecida en el artículo 125 de la Constitución federal y el último párrafo del artículo 137 de la Constitución de Nayarit, es decir, deben de elegir el cargo que más les convenga. ${ }^{21}$

Es importante destacar que los integrantes de los Ayuntamientos no pueden participar en las elecciones inmediatas a la conclusión de su encargo para ser integrantes del mismo Ayuntamiento, regla que también aplica para los miembros designados del Concejo Municipal; ${ }^{22}$ esto es, el presidente no puede postularse para ser síndico o regidor, ni estos para ser presidente municipal. Lo anterior tiene sustento en una concepción amplia del principio de no reelección; pues aún que no resultan postulados para un mismo puesto, lo cierto es que los ciudadanos votarían dos o más veces por el mismo ciudadano para integrar un mismo órgano colegiado.

\section{III.2 Incompatibilidad del gobernador}

Cuando una persona se encuentre ocupando el cargo de gobernador constitucional:

a) Para ser presidente municipal, síndico o regidor, deberá estar separado del cargo cuando menos 90 días antes de la elección. ${ }^{23}$

b) Para ser diputado local, tendrá que separarse del cargo cuando menos 90 días antes de la elección. ${ }^{24}$

c) Tiene impedimento absoluto para ser diputado federal o senador de la República, no solamente durante el periodo del encargo, sino aún cuando se separare definitivamente de él. ${ }^{25}$

\footnotetext{
${ }^{20}$ Op. cit. nota 13. Por su parte, la Ley Municipal para el Estado de Nayarit, señala: "Artículo 30.- Los Ayuntamientos de cada municipio se integran por un presidente municipal, un síndico y regidores de mayoría relativa y de representación proporcional, electos de conformidad a lo dispuesto por la Constitución Política del Estado, la Ley Electoral del Estado de Nayarit y el presente ordenamiento." "Artículo 31.- Para ser miembro de los Ayuntamientos se requiere cumplir con los requisitos que establecen la Constitución Política del Estado, la Ley Electoral del Estado de Nayarit y el presente ordenamiento."

${ }^{21}$ Op. cit. nota 15 .

${ }^{22}$ Véase artículo 107 de la CPELSN, que en la parte relativa establece: "Las personas que por elección indirecta o por nombramiento o designación de alguna autoridad competente, desempeñen las funciones propias de esos cargos, cualesquiera que sea la denominación se les dé, no podrán ser reelectos para el periodo inmediato (...)."

${ }^{23}$ Véase artículo 109, fracción IV, de la CPELSN.

${ }^{24}$ Op. cit. nota 13.

${ }^{25}$ Op. cit. nota 14. 
d) Para ser presidente de la República, debe separarse de su puesto seis meses antes del día de la elección de conformidad con el artículo 82 de la Constitución federal. ${ }^{26}$

III.3 Incompatibilidad de los diputados locales

La persona que en un momento dado se encuentre ejerciendo el cargo de diputado local:

a) Para ser gobernador, requiere separarse del cargo por lo menos 90 días antes de la elección. ${ }^{27}$

b) Para ser presidente municipal, síndico o regidor, debe separarse del cargo por lo menos 90 días antes de le elección ${ }^{28}$

c) Para ser presidente de la República, diputado federal o senador, la Constitución federal no exige separarse del cargo; por lo tanto, de resultar electo, deberá elegir entre ambos el que quiera desempeñar, de conformidad con lo establecido en el artículo 125 de la Constitución federal. ${ }^{29}$

III.4 Incompatibilidad de los diputados federales

Si una persona ocupa el cargo de diputado federal, deberá separarse del cargo, en los casos siguientes:

a) Para ser gobernador, por lo menos 90 días antes de la elección. ${ }^{30}$

b) Para ser diputado local, por lo menos 90 días antes de la elección ${ }^{31}$

c) Para ser miembro del Ayuntamiento, estar separado del cargo lo menos 90 días antes de la elección. ${ }^{32}$

d) Para ser Senador, puede postularse sin necesidad de separarse del cargo toda vez que si bien es cierto los diputados federales y los senadores pertenecen a un mismo poder político, se trata de dos órganos distintos con facultades claramente diferenciadas, de manera que quien se desempeñe como senador habiendo sido diputado, no podrá influir en las actividades de la Cámara de Diputados o viceversa; este criterio se encuentra inmerso en la jurisprudencia 12/2000, emitida por el Tribunal Electoral del Poder Judicial de la Federación; de rubro NO REELECCION, ALCANCE DE ESTE PRINCIPIO EN LOS AYUNTA-

\footnotetext{
${ }^{26}$ Véase artículo 82, fracción VI, de la CPEUM que establece: (Para ser Presidente se requiere) "VI. No ser secretario o subsecretario de Estado, Procurador General de la República, gobernador de algún estado ni jefe de Gobierno del Distrito Federal, a menos de que se separe de su puesto seis meses antes del día de la elección (...)".

27 Op. cit. nota 16.

${ }^{28}$ Op. cit. nota 20.

${ }^{29}$ Véase artículo 125 de la CPEUM.

${ }^{30}$ Op. cit. nota 16.

${ }^{31}$ Op. cit. nota 13 .

${ }^{32}$ Véase artículo 109, fracción IV, de la CPELSN.
} 
MIENTOS. Sin embargo, de resultar electo deberá atender lo dispuesto en el artículo 125 de la Constitución federal; esto es deberá elegir entre ambos el que quiera desempeñar. ${ }^{33}$

Ahora bien, no puede pasar de vista que el principio de no reelección para diputados federales y senadores de la República se encuentra prohibido por disposición expresa del artículo 59 de la Constitución federal, el cual dispone que no pueden ser reelectos para el periodo inmediato, pero no debe confundirse con el hecho de la continuidad que una persona puede tener alternativamente en cada Cámara.

e) Para ser Presidente de la República , el diputado federal no necesita separarse del cargo; e igual que en el supuesto anterior, en caso de resultar electo deberá elegir entre ambos cargos, el que quiera desempeñar, conforme al multicitado artículo 125 de la Carta Magna.

III.5 Incompatibilidad de los senadores

La persona que en un momento dado sea Senador de la República, y dentro del periodo de su encargo desee participar en procesos electorales, tendrá que separarse del mismo de la siguiente manera:

a) Para ser gobernador, debe estar separado por lo menos 90 días antes de la elección. ${ }^{34}$

b) Para ser diputado local, separarse del cargo por lo menos 90 días antes de la elección. ${ }^{35}$

c) Para ser presidente, síndico o regidor del Ayuntamiento, tendrá que separarse del cargo por lo menos 90 días antes de le elección. ${ }^{36}$

d) Para ser diputado federal, no tiene necesidad de separarse del cargo, pero de resultar electo, debe elegir entre ambos el que le convenga.

e) Para ser presidente de la República, no necesita separarse del cargo; e igual que en el supuesto anterior, deberá elegir el que quiera desempeñar entre ambos cargos.

A manera de colofón podemos señalar que la separación del cargo popular, a fin de poder ocupar otro también de elección popular, es un requisito que tiene por objeto, en estricto sentido, garantizar la compatibilidad de funciones; sin embargo, en determinados casos, no se requiere la separación anticipada del puesto, como por ejemplo cuando un diputado local en funciones, aspire a ocupar una curul del Congreso de la Unión; lo anterior, no necesariamente tendría como consecuencia la inelegibilidad del candidato, pues con ello quedaría limitado negativamente el derecho político-electoral de ser votado. En efecto, si una persona que ocupa ya un cargo de elección popular y aspira a otro puesto también de elección popular sin antes separarse de su cargo que ya ostentaba, podría pensarse que se atenta contra la equidad en la contienda electoral, principio constitucional de las elecciones democráticas en

\footnotetext{
33 Op. cit. nota 26.

34 Op. cit. nota 16.

35 Op. cit. nota 13 .

36 Op. cit. nota 20. 
un Estado de derecho, pero, se insiste, que si el legislador no previó en la ley como requisito para ocupar un puesto de elección popular la separación de un cargo, es evidente que cualquier restricción que no se encuentre establecida en tal marco jurídico afectaría el derecho fundamental de los ciudadanos de votar y ser votado.

Sin embargo, por mandato constitucional, ninguna persona puede ostentar simultáneamente dos o más cargos de elección popular; por lo que invariablemente debe elegir el que más le convenga, ya sea atendiendo a lo establecido en el último párrafo del artículo 137 de la Constitución local, en caso de cargos correspondientes al ámbito estatal, o bien conforme a lo establecido en el artículo 125 de la Constitución federal.

A manera de ejemplo, en el estado de Colima en el año 2009, se suscitó una controversia cuando un diputado en funciones sin separarse del cargo que ostentaba participó en las elecciones para ser presidente municipal y, a la postre, resultó ganador.

En dicha entidad, los requisitos a que deben ceñirse quienes aspiren a ocupar un cargo de elección popular en un municipio son, entre otros, el de separarse del cargo; sin embargo, tal restricción va dirigida a cualquier servidor público en ejercicio, ya de la Federación, del estado o del municipio; y podría suponerse que dentro de esta categoría comprendiera a los diputados. Todo lo contrario, pues el artículo 27 de la ley municipal, de manera expresa señala un catálogo de servidores públicos sin que en ellos se encuentren incluidos los diputados.

Debido a esa problemática, una vez impugnada la elegibilidad del candidato, la sala regional Toluca inaplicó el artículo 27 de la ley municipal del estado, al considerar que atentaba contra el principio de inequidad en la contienda electoral.

Los razonamientos de la sentencia para determinar la inelegibilidad del candidato, fueron centralmente los siguientes: ${ }^{37}$

a) Existía un conflicto de interpretación, puesto que una de las formas en que podía presentarse una colisión en el sistema jurídico, se daba cuando existían interpretaciones de preceptos normativos que resultaran incompatibles de manera parcial o total, siendo que en la especie, tanto la Constitución local como la ley municipal, establecían elementos diferentes para que los partidos políticos tuvieran derecho a postular candidatos para integrar los Ayuntamientos.

b) En ese sentido, si bien el cargo de diputado local no se encontraba dentro del catálogo precisado por la ley municipal del estado de Colima, no se podía negar que el funcionario cuestionado era servidor público, puesto que además de ejercer facultades inherentes a su propia función pública, tenía constitucional y legalmente un cúmulo de facultades que debía ejercer para cumplir con el mandato que le había sido conferido.

Ante tal determinación, la Sala Superior del Tribunal Electoral del Poder Judicial de la Federación declaró fundados los agravios del inconforme y revocó la sentencia emitida por la sala regional, toda vez que ésta, al inaplicar el artículo 27 de la ley municipal, realizó una interpretación restrictiva en perjuicio del derecho del voto pasivo, en virtud de que la legislación no prevé expresamente que los diputados tengan la obligación de separarse del cargo para obtener el cargo de presidente municipal; y con mayor razón, cuando se está en presencia de un derecho fundamental el cual debe ser ampliado y no limitado, de ahí que si el legislador

37 Resolución SUP-REC-18/2009 emitida por la Sala Superior del Tribunal Electoral del Poder Judicial de la Federación. 
no tuvo la intención de distinguir a los diputados dentro del catálogo de funcionarios que tienen obligación de separase del cargo; cualquier limitación contraviene al derecho fundamental de votar y ser votado. Atendiendo a ese criterio, la interpretación de la normatividad del sistema jurídico electoral, debe perseguir maximizar en la medida de lo posible el ejercicio de los derechos políticos electorales del ciudadano.

\section{LA INCOMPATIBILIDAD PARLAMENTARIA LOCAL}

Sin demérito del resto, la incompatibilidad parlamentaria local merece un estudio aparte por la manera en cómo la Constitución y las normas congresionales se ocupan de ella. ${ }^{38} \mathrm{El}$ artículo 31 constitucional, establece:

Artículo 31.- Los Diputados no podrán, durante el período de sus funciones, desempeñar otra comisión o empleo de la Federación, del estado o municipio, por el cual se disfrute sueldo, sin licencia previa de la Cámara o Diputación Permanente en su caso; pero entonces cesarán en sus funciones representativas mientras dure la nueva ocupación.

Para ejercer el cargo legislativo, también debe atenderse el principio de compatibilidad de funciones. Mientras la inelegibilidad evita situaciones de inequidad para obtener el cargo legislativo, la incompatibilidad se manifiesta en el desempeño simultáneo de dos o más cargos públicos, por lo que su normatividad es observable a partir de que se obtiene el cargo legislativo, no antes.

Definida como causa de incompatibilidad el conjunto de actividades o cargos que no está permitido desempeñar simultáneamente con el mandato parlamentario, su finalidad es garantizar la independencia, libertad y eficacia en el ejercicio de la representación; definir el sistema político, manteniendo la neutralidad en el ejercicio de cargos públicos y proteger una ética en el ejercicio del cargo, evitando que se emplee para fines particulares y que se cuente con múltiples fuentes de ingresos.

Además, se busca evitar que se afecte la autonomía del estado, el desarrollo adecuado de los programas institucionales y el uso, custodia y acrecentamiento de los bienes y recursos públicos.

Es así, que el citado artículo 31 asegura la estabilidad de las funciones camerales, al prohibir a los diputados que durante el periodo de su encargo, desempeñen otra comisión o empleo por los cuales se disfrute sueldo. Este precepto encuadra en la prohibición de concentrar poderes constituidos en una sola persona o corporación, en términos de los artículos 22 y 23 de la misma Constitución local. Lo demanda también el principio de independencia y pluralidad del órgano legislativo.

La hipótesis principal que podemos sustraer es que los diputados pueden superar esta prohibición siempre que se separen del cargo, mediante la licencia respectiva.

De acuerdo con el estatuto parlamentario previsto en la ley orgánica, y con criterios jurisprudenciales de la Sala Superior del Tribunal Electoral del Poder Judicial de la Federación, el derecho a ser votado comprende también ser postulado candidato $y$, de resultar triunfador en los comicios, ocupar el cargo, por lo cual debe entenderse incluido el derecho de ejercer las funciones inherentes durante el periodo de su comisión.39 Por esa razón, el legislador solo puede quedar separado, suspendido o removido mediante los procedimientos previstos en la misma Constitución, en el caso que nos ocupa viene a ser la solicitud de licencia para

\footnotetext{
${ }_{38}$ Nos seguimos refiriendo a la Constitución Política de Nayarit.

39 Jurisprudencia 20/2010, unanimidad de votos. 
separarse voluntariamente del cargo, misma que puede tramitarse ante el pleno de la Cámara de Diputados o, durante sus recesos, ante la Diputación Permanente, conforme la fracción III, último párrafo, del artículo 60 constitucional.

Por otra parte, las incompatibilidades lamentablemente no se extienden a conflictos de interés vinculados con el ejercicio de actividades profesionales, empresariales o comerciales, exceptuando a las actividades académicas y de investigación en instituciones educativas públicas o privadas.

Resulta por ello paradójico que la Constitución esté planteando una dedicación completa al cargo legislativo, tratando de evitar que se distraigan en otras ocupaciones ajenas a la función representativa pero, al mismo tiempo, deja abierta la puerta para que los diputados realicen actividades de liderazgos, funciones directivas y comisiones partidistas, así como gestiones de representación sindical o gremial, asesorías, consultorías y diversas ocupaciones de índole privadas, que cotidianamente desempeñan de manera simultánea con el cargo representativo.

De ahí que, atendiendo a su propia naturaleza autonormativa, el Reglamento para el Gobierno Interior del Congreso, en sus artículos 13 y 14, tiene a bien desglosar y complementar armónicamente otros supuestos más allá del propio dispositivo constitucional: ${ }^{40}$

Artículo 13. Los diputados no podrán aducir ocupaciones particulares para excusarse del cumplimiento de los deberes legislativos o de representación. Tampoco podrán invocar o hacer uso de su condición de legisladores para el ejercicio de actividades de orden mercantil, industrial o profesional.

Artículo 14. El desempeño del cargo de diputado es incompatible con cualquier empleo, cargo, comisión o representación de la Federación, estados o municipios, con excepción de las actividades docentes, sindicales, partidista, literarias, de creación artística, de investigación científica, tecnológica, técnica o humanística, siempre que sean compatibles con sus funciones y no perciba remuneración alguna por ellas.

Subyace claramente en ambos preceptos un mandato negativo impuesto a los legisladores a fin de que atiendan prioritariamente las funciones que los electores les encomendaron y que de acuerdo con la ley orgánica, en su artículo $3^{\circ}$, son las siguientes: ${ }^{41}$

Artículo $3^{\circ}$. Los diputados que integran la Asamblea, asumirán sus cargos y ejercerán sus funciones con apego al mandato constitucional y demás disposiciones legales aplicables, por lo que deberán atender primordialmente:

a) La actividad legislativa;

b) El ejercicio de las facultades de fiscalización de los recursos públicos y de la gestión financiera en los términos de la Constitución local;

c) La gestión y procuración de la solución a los problemas sociales que demande el interés público de sus distritos y de la entidad.

De manera que si se adminiculan entre sí, tenemos bien desarrollado el sistema normativo de incompatibilidades y sus excepciones, en el ámbito parlamentario estatal.

\footnotetext{
${ }^{40}$ Nos referimos al reglamento que rige en el Congreso de Nayarit.

${ }^{41}$ Véase, MADERO ESTRADA, José Miguel, Ley Orgánica del Poder Legislativo de Nayarit, Comentada, Poder Legislativo de Nayarit, Centenario de la Revolución y Bicentenario de la Independencia, 2010, pp. 9-23.
} 
Hacemos un paréntesis para destacar que, lo dicho particularmente en el artículo 14, es un tanto opinable porque equipara como excepciones compatibles a las actividades docentes, sindicales, literarias, de creación artística, de investigación científica, tecnológica, técnica o humanística, con las funciones partidistas, lo cual, como ya se señaló, nos parece inexacto, ya que han sido precisamente las actividades de naturaleza político-electoral, las que distraen profusamente la atención y falta de dedicación de los legisladores en tareas propias de la agenda parlamentaria y política del Congreso.

Podemos inferir que las actividades docentes, académicas o de investigación, mediante su práctica constante, fomentan una mejor preparación y especialización del legislador, a condición de cuidarse la compatibilidad de los horarios para cumplir con esas labores.

El artículo 31 constitucional tiene, sin embargo, el defecto de que en caso de incumplimiento de solicitar previamente la licencia, no existe sanción para el diputado infractor, siendo que se haría merecedor inclusive a la pérdida del cargo. ${ }^{42}$

Por consiguiente, es aconsejable la reforma constitucional para aclarar el escenario completo del sistema de incompatibilidades, puesto que deja un vacío en la regulación de conflictos de intereses privados y sociales que eventualmente podrían contraponerse con la labor legislativa y ello, lamentablemente afecta la independencia y libertad del legislador.

Es aconsejable prohibir genéricamente la acumulación de cargos, pues si en un momento dado el elegido tiene el derecho de optar por el puesto o responsabilidad de su preferencia, se requiere que la ratio juris de la incompatibilidad llegue más lejos con el fin de impedir situaciones indebidas como, por ejemplo, cuando un servidor público acumule cargos en la administración centralizada y en la paraestatal, o en distintas dependencias del mismo órgano estatal o municipal, de manera simultánea; cuando los funcionarios no cumplan con sus horarios de trabajo; cuando litiguen contra el Estado, presten servicios de consultoría o asesoría encubiertos en despachos profesionales y cuando su actividad profesional o técnica genere intereses que comprometan su desempeño en el servicio.

Por todo lo visto, las incompatibilidades parlamentarias pueden clasificarse conforme al desempeño de: a) funciones públicas, b) funciones privadas, y c) funciones electorales.

\section{CONCLUSIÓN}

Podemos considerar que el requisito de separación del cargo de los servidores públicos no deriva de la posibilidad de que éstos desvíen los recursos de que disponen para influir en las campañas electorales. Para prevenir y sancionar tales conductas, existe un régimen de

\footnotetext{
${ }^{42}$ Aunque si bien se trata de otro tema, la Constitución tampoco aclara qué pasa con las prerrogativas a favor del diputado que obtuvo licencia, es decir si pese a la separación del cargo, subsisten a favor suyo la inviolabilidad y la inmunidad procesal, hasta que aparezca alguna causa de terminación definitiva del cargo. Ciertamente, como el fuero no es propio y verdadero derecho subjetivo del que puede disponer libremente quien lo disfruta, los miembros del Congreso no pueden renunciarlo porque se trata de una prerrogativa parlamentaria y de orden público. Debido a esa irrenunciabilidad es que la Suprema Corte no acepta que se suspenda o concluya por licencia a la que considera como una simple autorización de la Cámara para que sus miembros se ausenten sin incurrir en alguna causal de sanción, y aun cuando significa una suspensión en el ejercicio del cargo, no implica, en razón de su temporalidad, la pérdida de los derechos inherentes a él. El criterio de la Corte es que la licencia no priva al legislador del fuero, sino que este concluye con la muerte, por renuncia, por el transcurso del tiempo que dure la función o porque el interesado no acuda a rendir protesta. En nuestra opinión, la separación del legislador, aun sea temporal, da lugar, materialmente, a la suspensión de algunas prerrogativas como la de percibir dieta o ejercer alguna función directiva en el Congreso.
} 
responsabilidades de los servidores públicos además de las disposiciones en ese sentido contenidas en el derecho penal electoral.

El requisito de separación del cargo, es en realidad una restricción -en nuestro concepto legal, racional y constitucional- para la postulación del ciudadano que ya ejerce un cargo público, pero para evitar la desventaja de quien no ejerce ninguno y no cuenta con una plataforma pública, recursos y apoyos, como los que tienen algunos de los servidores públicos protegiendo en todo momento el principio de equidad en la contienda electoral. Y por otro lado, para aquellos servidores públicos que la Constitución o las leyes les exige separarse del cargo para acceder a otro, no por la vía del sufragio sino del nombramiento, deriva de la posibilidad de que puedan ejercer simultáneamente dos o más empleos cargos o comisiones. Esta restricción radica fundamentalmente en la obligación de dedicarse de tiempo completo al desempeño de sola una función por lo que expresa marcadamente un deber ético de los servidores públicos.

Al ser la representación popular un principio básico de la democracia reconocido en la Constitución, la protección de los derechos político-electorales del ciudadano comprende, integralmente, el derecho a votar, a ser votado y también el de ser postulado candidato a integrar los órganos estatales y a ocuparlos, en razón de lo cual también debe entenderse incluido el derecho a ejercer las funciones inherentes durante el periodo del encargo.

Ello otorga un estatus constitucional al sistema representativo, toda vez que los representantes populares deben desplazarse en el marco del derecho, pues la elegibilidad no es un cheque en blanco, sino una garantía para el acceso y ejercicio de la función representativa.

Si por calidades jurídicas, en sentido amplio, puede entenderse a las capacidades, aptitudes, preparación profesional, edad, vinculación, arraigo o liderazgo social y demás circunstancias que ponen de relieve el perfil idóneo para desempeñar con eficiencia y eficacia un cargo representativo, resulta indispensable que dentro de una atmósfera de libertad, de cara a la división de poderes, se regule el principio de incompatibilidad de funciones como un instrumento ético de nuestra democracia, no solamente como una regla de acceso al poder, sino de ejercicio ajustado a la ley, con rendición de cuentas a los ciudadanos y transparencia, todo ello para garantizar integralmente la independencia en el desempeño de las funciones públicas.

ARTEAGA NAVA, Elisur, Derecho Constitucional, Colección Juristas Latinoamericanos, Ed. Oxford University Press- Harla, 1998.

BURGOA ORIHUELA, Ignacio, Derecho Constitucional Mexicano, Editorial Porrúa, 1997.

DOSAMANTES TERÁN, Jesús Alfredo, Diccionario de Derecho Electoral, Editorial Porrúa, México, 2004.

FERNÁNDEZ RUÍZ, Jorge, Poder Legislativo, Editorial Porrúa y UNAM, México, 2010.

MADERO ESTRADA, José Miguel, Constitución Politica de Nayarit, origen y reforma (1918-1996); UAN.

Guía Temática de la Constitución Política del Estado de Nayarit, Unidad Académica Facultad de Derecho, México, UAN, 2012. 

lativo de Nayarit, Centenario de la Revolución y Bicentenario de la Independencia, 2010 .

RODRÍGUEZ LOZANO, Amador y Fernández Ruíz, Jorge, Constitución Política de los Estados Unidos Mexicanos, Comentada y Concordada; tomos III y V, IVJ, UNAM, Ed. Porrúa; México, 2000.

\section{LEGISLACIÓN}

Constitución Política de los Estados Unidos Mexicanos, última reforma al 26 de febrero de 2013. http://www.diputados.gob.mx/LeyesBiblio/pdf/1.pdf

Constitución Política del Estado libre y Soberano de Nayarit, última reforma al 21 de enero de 2013. http://www.congresonay.gob.mx/Portals/1/Archivos/compilacion/constitucion/constitucion_politica_estado_nayarit.pdf

Ley Municipal para el Estado de Nayarit, última reforma al 3 de octubre de 2012. http://

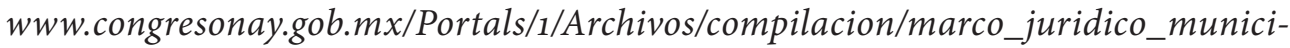
pal/Municipal_para_el_Estado_de_Nayarit_\%28Ley\%29.pdf

Ley Orgánica del Poder Judicial para el Estado de Nayarit, última reforma al 4 de junio de 2011. http://www.congresonay.gob.mx/Portals/1/Archivos/compilacion/leyes_organicas/ Poder_Judicial_para_el_Estado_de_Nayarit.\%20\%28Ley\%2oOrg\%C3\%A1nica\%2o del\%29.pdf 